\title{
Isolamento de fungos associados a grãos de café cv. Iapar 59 de origem de solo e árvore em diferentes tempos de colheita
}

\author{
Fungi isolation associated with coffee grains of the cv. Iapar 59 picked \\ from the ground and trees at different harvest times
}

\author{
Angela BOZZA ${ }^{1 \star}$, Sabina Moser TRALAMAZZA ${ }^{1}$, Dalton Tadeu REYNAUD ${ }^{2}$, Juarez GABARDO ${ }^{3}$, \\ Julio César VALASKI ${ }^{3}$, Paulo Roberto MARANGONI ${ }^{1}$, Ida Chapaval PIMENTEL ${ }^{1}$
}

\section{Resumo}

O Brasil vem perdendo espaço no mercado internacional devido à piora da qualidade do café. As substâncias tóxicas liberadas pelos fungos além de alterarem a qualidade da bebida, também podem ser prejudiciais à saúde dos consumidores. O objetivo do presente trabalho foi o isolamento de fungos a partir de grãos de café da variedade IAPAR 59, relacionando-os com a qualidade da bebida. Foram realizadas colheitas de grãos da árvore e do solo em diferentes tempos (0, 30, 60, 90 e 120 dias). O isolamento dos fungos foi feito pelo método Pour-plate e para a identificação dos fungos utilizou-se o Microcultivo e a Microscopia Eletrônica de Varredura (MEV). Houve diferença significativa no número absoluto de fungos encontrados nos grãos da árvore (5393), em relação aos grãos coletados no solo (1523). Foram identificados 7 gêneros: Absidia, Acremonium, Aspergillus, Fusarium, Mucor, Paecilomyces e Penicillium. Verificaram-se elevados níveis de Ocratoxina A em algumas amostras de café. A bebida perdeu a qualidade em função do tempo de permanência dos grãos na árvore e no solo, portanto, para a obtenção de uma bebida de melhor qualidade, deve-se evitar a permanência prolongada dos grãos em seus locais de origem.

Palavras-chave: qualidade da bebida; IAPAR 59; fungos; Coffea arabica.

\begin{abstract}
Brazil is losing space in the international market due to the worsening in the quality of the coffee. The toxic substances released by fungi besides altering the quality of the drink, can also be harmful to the consumers' health. The purpose of this work was the isolation of fungi from coffee beans of the variety IAPAR 59 to analyze their effect on the quality of the drink. Grains were harvested from trees and were picked from the ground at different times $(0,30,60,90$, and 120 days). The isolation of the fungi was made by the method "Pour-plate", and the Microcultive and Electronic Scanning Microscopy (MEV) was used to identify the fungi. There was a significant difference in the absolute number of fungi found in grains from trees (5393) in relation to the grains picked from the ground (1523). Seven genera were identified: Absidia, Acremonium, Aspergillus, Fusarium, Mucor, Paecilomyces e Penicillium. High levels of Ochratoxin A in some samples of coffee were identified. The drink lost quality according to the harvest time and the period the beans were left in the ground. In order to guarantee a better quality of the drink, it is recommended avoiding leaving the beans in their places of origin for too long before harvesting

Keywords: quality of the drink; IAPAR 59; fungi; Coffea arabica.
\end{abstract}

\section{Introdução}

O agronegócio mundial do café engloba, anualmente, recursos que chegam a 91 bilhões de dólares e envolve meio bilhão de pessoas, ou $8 \%$ da população mundial. É nesse mercado gigantesco que está centrado o interesse da cadeia produtiva do café brasileiro, que chegou a contribuir com mais de 30\% da produção mundial (EMBRAPA, 2007).

Durante muito tempo, o Brasil foi considerado como o maior produtor de café, sendo este café consumido pelo mercado, independente da sua preferência. Enquanto isso, outros países, como a Colômbia, investiram em qualidade e marketing, conseguindo uma maior valorização em relação ao café brasileiro, considerado de uma qualidade única e baixa (CARVALHO, 2001).
O tempo de permanência dos frutos no chão está relacionado com o aumento na porcentagem de fungos encontrados no interior dos grãos (KRUG, 1940). Além da presença dos fungos, outros fatores alteram a qualidade da bebida, tais como: umidade, temperatura, altitude, tipo de solo, pluviosidade, estágio do fruto quando a colheita é realizada, processo de fermentação, entre outros de menor importância (KRUG, 1947).

Os fungos também podem produzir metabólitos tóxicos quando estão se multiplicando nos alimentos. Estes metabólitos recebem a denominação genérica de "micotoxinas" e correspondem a produtos metabólicos secundários que, quando ingeridos com os alimentos, causam alterações

Recebido para publicação em $8 / 11 / 2007$

Aceito para publicação em 8/7/2009 (002995)

${ }^{1}$ Laboratório de Microbiologia e Biologia Molecular - Labmicro, Departamento de Patologia Básica, Universidade Federal do Paraná - UFPR,

Rua Franciso H. dos Santos s/n, Jardim das Américas, CEP 81531-970, Curitiba - PR, Brasil, E-mail: angela.bozza@gmail.com

${ }^{2}$ Centro Universitário Campos Andrade - UNIANDRADE

${ }^{3}$ Departamento de Genética, Universidade Federal do Paraná - UFPR, Curitiba - PR, Brasil

${ }^{*}$ A quem a correspondência deve ser enviada 
biológicas prejudiciais tanto no homem quanto nos animais (micotoxicoses) (FRANCO; LANDGRAF, 2005).

Estudos têm demonstrado que a ocratoxina A tem ação nefrotóxica, teratogênica, carcinogênica, imunossupressora e está relacionada com a nefropatia endêmica dos Balcãs. Mais recentemente foram descritas evidências de uma possível correlação entre ocratoxina A e desenvolvimento de tumores do trato urinário de seres humanos na Bulgária (PRADO et al., 2000).

Estratégias eficientes de controle da presença de Ocratoxina A em café devem ser adotadas, por representarem entraves na comercialização desse produto e também por colocarem em risco a saúde dos consumidores. Nesse sentido, os mercados importadores estão cada vez mais exigentes, reduzindo os níveis de tolerância da ocratoxina A (FURLANI; SOAREZ; OLIVEIRA, 1999). Em alguns países europeus o nível máximo de ocratoxina A foi delimitado em $5 \mu \mathrm{g} / \mathrm{kg}$ em cereais e $1 \mu \mathrm{g} / \mathrm{kg}$ em alimentos destinados a crianças. No Brasil ainda não foram adotadas medidas semelhantes, existindo legislação somente para aflatoxinas (PRADO et al., 2000).

A cafeicultura é uma das principais atividades agrícolas do Brasil e, para a sua sobrevivência, acredita-se que o País precisa seguir o caminho da qualidade. A bebida do café é fator importante na comercialização do produto e a sua caracterização é feita por degustadores (prova de xícara). O café brasileiro é classificado em tipo e bebida. O tipo se refere aos defeitos existentes no café, como grãos deteriorados, pretos, ardidos, verdes, quebrados, conchas, chochos, cocos marinheiros, cascas, torrões, pedras, etc. (PIMENTA; VILELA, 2003).

A “prova da xícara” é uma prova subjetiva em que provadores treinados distinguem diferentes padrões de bebida. Esta é realizada com o café preparado para ser degustado, sendo avaliado quanto ao seu sabor e aroma. Tecnicamente, a classificação oficial do café pela bebida é feita pelos denominados padrões de bebida, que recebem as seguintes denominações: Estritamente Mole, bebida de sabor suavíssimo e adocicado; Mole, bebida de sabor suave, acentuado e adocicado; Apenas Mole, bebida de sabor suave com leve adstringência; Dura, bebida com sabor adstringente e gosto áspero; Riada, bebida com leve sabor de iodofórmio ou ácido fênico; Rio, bebida com sabor forte e desagradável lembrando iodofórmio ou ácido fênico; Rio Zona, bebida de sabor e odor intoleráveis ao paladar e ao olfato. São denominações técnicas que mostram a variedade de sabor e qualidade e que interferem também na cotação do seu preço no mercado (CARVALHO; CHALFOUN, 1999).

O principal objetivo deste trabalho foi o isolamento de fungos associados aos grãos de café cv. Iapar 59 em diferentes tempos de colheita e diferentes origens (solo e árvore).

\section{Material e métodos}

Material biológico: Os grãos de café analisados são da variedade IAPAR 59, pertencem à safra de 2004/2005 e apresentam resistência à ferrugem. Foram coletados na Estação Experimental do Instituto Agronômico do Paraná (IAPAR), localizada na cidade de Londrina, no Estado do Paraná.
Dividiu-se a plantação em parcelas com 50 cafeeiros cada. O experimento iniciou-se com a retirada dos frutos dos cafeeiros e dos frutos caídos diretamente no solo. A cada 30 dias foram coletados, destas parcelas, frutos da árvore e frutos que caíram no chão, totalizando 5 tempos de colheita. A colheita foi feita pelo método da derriça no chão, seguida de secagem e armazenamento dos grãos, realizada pelos técnicos da Estação Experimental do IAPAR. Foram coletadas 4 amostras em cada um dos 5 tempos, sendo eles 0, 30, 60, 90 e 120 dias (27/06, 27/07, 27/08, 27/09 e 27/10). Totalizaram-se 40 amostras, sendo 20 amostras com grãos originados do solo e 20 amostras com grãos originados da árvore. As amostras foram recebidas após a secagem e beneficiamento dos grãos, juntamente com os resultados da prova da xícara e dos testes de detecção da presença de Ocratoxina A, fornecidos pelo IAPAR.

Isolamento dos fungos: Para a determinação da população fúngica utilizou-se a técnica Pour-plate (APHA, 2005), modificada por Bozza e Pimentel (2006). Em um Erlenmeyer contendo $90 \mathrm{~mL}$ de água peptonada, colocaram-se $10 \mathrm{~g}$ de café moído, o qual permaneceu no agitador por 30 minutos a $36^{\circ} \mathrm{C}$. A inoculação foi feita em fluxo laminar, sendo 3 diluições $\left(10^{-1}\right.$, $10^{-2}$ e $10^{-3}$ ) com 4 placas cada diluição. Foi colocado $1 \mathrm{~mL}$ $(1000 \mu \mathrm{L})$ na placa e, posteriormente, verteu-se o meio BDA fundido, em temperatura média, e homogeneizou-se. Para preparar as demais diluições utilizaram-se tubos de ensaios contendo $9 \mathrm{~mL}$ de água peptonada. Para o isolamento dos fungos dos grãos foi utilizado o meio de cultura Ágar BDA (Batata Dextrose Ágar - Biobrás Diagnósticos - Montes Claros/ MG) juntamente com tetraciclina $(160 \mu \mathrm{L}$ para $400 \mathrm{~mL}$ de meio de cultura). As placas foram incubadas em estufa a $28^{\circ} \mathrm{C}$ por 4 dias.

Após o período de incubação realizou-se a contagem das colônias. $\mathrm{O}$ isolamento dos fungos foi realizado repicando as colônias em tubos de ensaio, com o meio de cultura BDA inclinado, e incubados em estufa com temperatura média de $28^{\circ} \mathrm{C}$ de 3 a 5 dias. Os isolados foram, então, agrupados de acordo com sua morfologia colonial.

Identificação dos isolados: Realizou-se a técnica do microcultivo (KERN; BLEWINS, 1999) em um isolado de cada grupo morfológico. Utilizaram-se lâminas de microcultivo com 7 e 14 dias de crescimento. A identificação foi realizada através de observações de corpos de frutificação ao microscópio óptico e da utilização de literatura especializada (KLICH; PITT, 1988; BARNETT; HUNTER, 1987; LARONE, 1987; HAZEN et al., 1973; MENEZES; OLIVEIRA, 1993; KERN, 1988; HERRERA; ULLOA, 1990; HOOG; GUARRO, 2004). Como método auxiliar na identificação realizou-se a microscopia eletrônica de varredura (MEV), segundo Stofella (1994).

Análise estatística: Os dados relativos ao número de colônias isoladas receberam tratamento estatístico, sendo transformados para $\log (\mathrm{x}+2)$, com o intuito de estabelecer sua normalidade. Realizou-se a Análise de Variância (ANOVA) segundo o delineamento inteiramente ao acaso (DIC), com esquema fatorial $2 \times 5$ com 16 repetições. Um dos fatores foi o local com dois níveis (solo e árvore) e o outro, o tempo de colheita com cinco níveis $(0,30,60,90$ e 120 dias após a primeira colheita). Quando foi encontrada significância para o teste $F(\mathrm{p}>0,05)$, 
complementou-se a ANOVA com o teste de Tukey para médias ( $\mathrm{p}>$ 0,05) (PIMENTEL-GOMES, 1990; VIEIRA, 2006). O programa utilizado foi Assistat versão 7.4 beta (2007).

\section{Resultados e discussão}

Foram obtidos 6916 isolados fúngicos dos grãos de café de duas origens (solo e árvore), em 5 diferentes tempos de colheitas. Estes isolados foram classificados em 7 gêneros: Acremonium sp., Absidia sp., Aspergillus sp., Fusarium sp., Mucor sp., Paecilomyces sp. e Penicillium sp.

Houve diferença significativa no número absoluto de fungos encontrados na árvore (5393 isolados) e no solo (1523 isolados). Estes resultados não estão de acordo com os dados de Aeschbach et al. (2004), os quais, isolando fungos de grãos de café da variedade Iapar 59, associados à qualidade da bebida, constataram que dentre os 14 fungos isolados, 10 foram isolados de grãos coletados do solo. Estes resultados são, possivelmente, devido à maior exposição desses grãos aos fatores climáticos, como chuva, umidade e orvalho, propiciando maior possibilidade de infecção dos grãos coletados do solo, pelos fungos. O grande número de fungos isolados dos grãos de café provenientes da árvore (safra de 2004/2005) pode estar relacionado às condições climáticas que ocorreram durante o experimento, como mudança na umidade relativa do ar. A alta umidade relativa do ar e a alta temperatura podem propiciar a infecção e crescimento de microrganismos (PIMENTA; VILELA, 2003).

Os gêneros encontrados em maior número absoluto foram: Aspergillus sp1, Aspergillus sp3, Aspergillus sp7, Aspergillus sp10 e Aspergillus sp12. Os gêneros encontrados em menor número absoluto foram: Paecilomyces sp., Penicillium sp3, Aspergillus sp5, Aspergillus sp8 e Absidia sp. (Tabela 1).

Com relação aos gêneros isolados da árvore, foram encontrados em maior número: Aspergillus sp1 (2665 isolados), Aspergillus sp3 (431 isolados), Aspergillus sp10 (1071 isolados), Aspergillus sp12 (517 isolados). E em menor número: Paecilomyces sp. (9 isolados), Aspergillus sp8 (10 isolados) e Absidia sp. (3 isolados). O morfotipo Aspergillus sp5 não foi isolado a partir de grãos originados da árvore.

Os gêneros encontrados no solo foram: em maior número: Aspergillus sp7 (352 isolados), Aspergillus sp10 (481 isolados); e em menor número: Penicillium sp3 (1 isolado) e Absidia sp. (1 isolado). O morfotipo Aspergillus sp11 não foi isolado de grãos coletados do solo (Figura 1).

Foi constatada diferença significativa $(\mathrm{p}<0,01)$, relacionada ao número total de isolados encontrados nos grãos colhidos, provenientes do solo e da árvore, nos 5 diferentes tempos de colheita (Figura 2).

O número absoluto de fungos isolados dos grãos de café originados da árvore sofre, em geral, um decréscimo com o decorrer dos tempos de colheita. Entretanto, no tempo de 120 dias houve um leve aumento em relação ao tempo de 90 dias, fato que pode ter ocorrido, como já citado anteriormente, por uma mudança na umidade relativa do ar (PIMENTA; VILELA, 2003). O aumento na umidade relativa do ar associado a altas
Tabela 1. Número absoluto de gêneros isolados dos grãos de café cv. Iapar 59 da árvore e do solo da região de Londrina - PR (safra 2004/2005).

\begin{tabular}{|c|c|c|c|}
\hline Gêneros & $\begin{array}{c}\text { Número de } \\
\text { isolados da árvore }\end{array}$ & $\begin{array}{c}\text { Número de } \\
\text { isolados do solo }\end{array}$ & $\begin{array}{c}\text { Número total } \\
\text { de isolados }\end{array}$ \\
\hline Acremonium sp. & 82 & 87 & 169 \\
\hline Fusarium sp. & 43 & 13 & 56 \\
\hline Paecilomyces sp. & 9 & 6 & 15 \\
\hline Mucor sp1 & 74 & 160 & 234 \\
\hline Mucor sp2 & 17 & 7 & 24 \\
\hline Penicillium sp1 & 16 & 9 & 25 \\
\hline Penicillium sp2 & 14 & 5 & 19 \\
\hline Penicillium sp3 & 14 & 1 & 15 \\
\hline Aspergillus sp1 & 2665 & 187 & 2852 \\
\hline Aspergillus sp2 & 47 & 11 & 58 \\
\hline Aspergillus sp3 & 431 & 59 & 490 \\
\hline Aspergillus sp4 & 16 & 8 & 24 \\
\hline Aspergillus sp5 & 0 & 4 & 4 \\
\hline Aspergillus sp6 & 13 & 32 & 45 \\
\hline Aspergillus sp7 & 109 & 352 & 461 \\
\hline Aspergillus sp8 & 10 & 5 & 15 \\
\hline Aspergillus sp9 & 104 & 7 & 111 \\
\hline Aspergillus sp 10 & 1071 & 481 & 1552 \\
\hline Aspergillus sp11 & 138 & 0 & 138 \\
\hline Aspergillus sp 12 & 517 & 88 & 605 \\
\hline Absidia sp. & 3 & 1 & 4 \\
\hline Total & 5393 & 1523 & 6916 \\
\hline
\end{tabular}

temperaturas propicia uma maior infecção dos fungos. Neste caso específico, além do aumento do número absoluto de fungos da árvore, também houve um aumento na diversidade dos isolados.

O tempo com o maior número de morfotipos, isolados da árvore, foi o de 120 dias, com 18 morfotipos diferentes. Em seguida 0, 30 e 60 dias, com 16 morfotipos; e 90 dias com 13 morfotipos.

O decréscimo do número absoluto de fungos no decorrer dos tempos de colheita também foi observado nos fungos isolados de grãos provenientes do solo. Porém, observou-se que no tempo de 60 dias houve um aumento no número absoluto de fungos. Neste caso, o período da colheita foi permeado por chuvas e elevadas temperaturas, o que pode ter favorecido a infecção dos grãos por fungos. O tempo de 90 dias além de apresentar o menor número absoluto de fungos, também apresentou a menor diversidade em relação aos demais tempos de colheita.

O tempo de colheita com maior número de morfotipos, originados do solo, foi de 0 dia, com 17 morfotipos, seguido dos tempos 30 e 60 dias com 14 morfotipos, 120 dias com 13 morfotipos, e o tempo com menor número de espécies foi o de 90 dias, com 12 morfotipos.

Em relação à prova da xícara houve uma alteração na qualidade da bebida de grãos coletados de árvore em relação ao tempo de colheita. De dura, a bebida passou a ser qualificada 


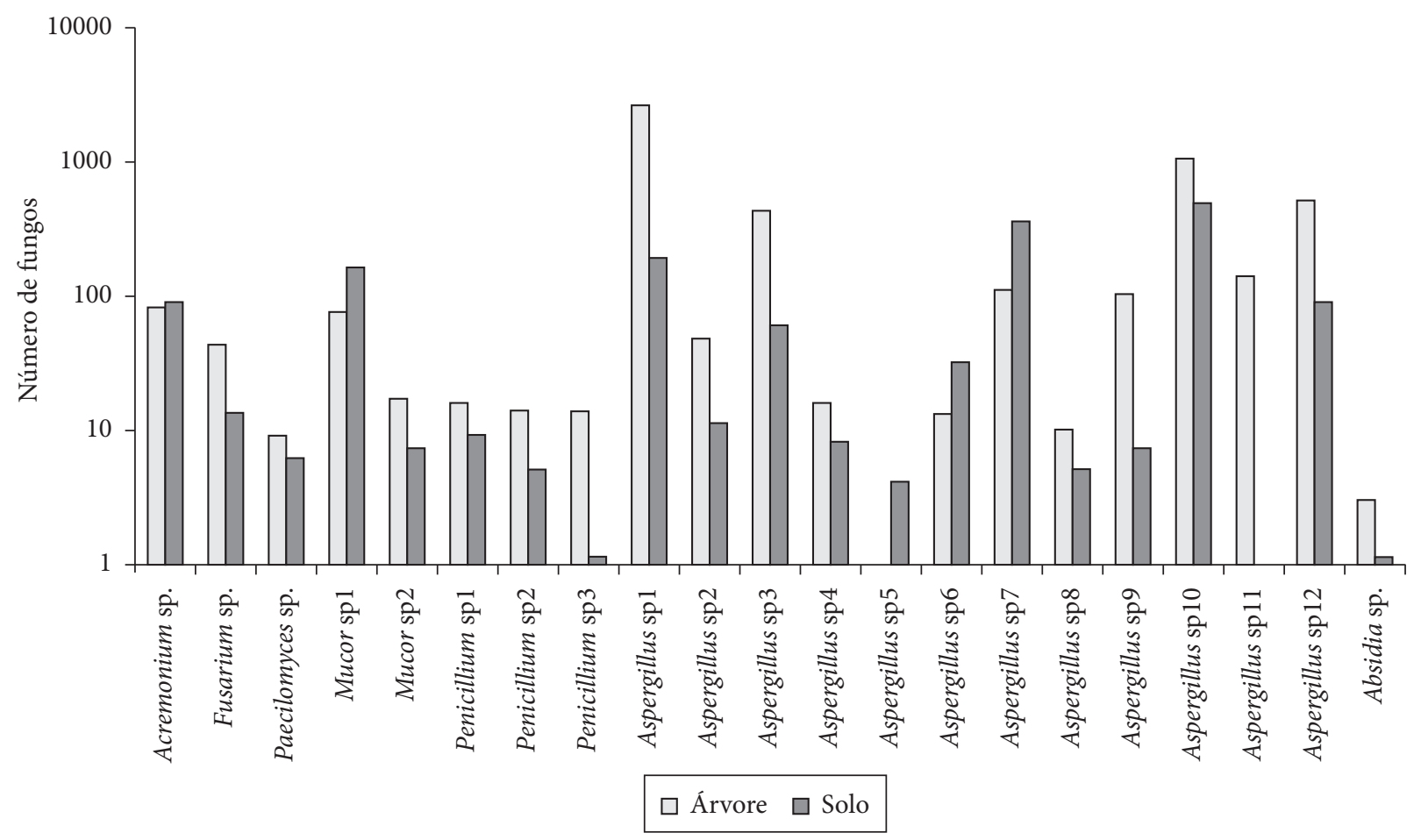

Figura 1. Distribuição do número absoluto de fungos isolados dos grãos de café cv. Iapar 59 da árvore e do solo da região de Londrina - PR (safra 2004/2005). A Figura se apresenta em escala logarítmica para que a ampla distribuição numérica seja mais facilmente visualizada. Fonte: $\mathrm{O}$ autor.

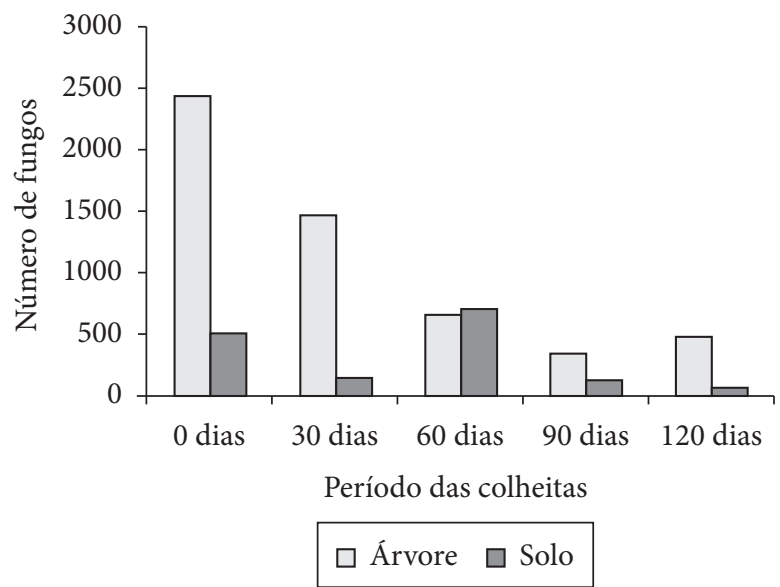

Figura 2. Número absoluto de fungos isolados dos grãos de café cv. Iapar 59 da árvore e do solo da região de Londrina - PR (safra 2004/2005) em relação aos tempos de colheita. Fonte: O autor.

como Rio. A bebida de grãos coletados do solo também sofreu alteração, de Dura, passou a ser classificada como Riada/Rio (Figura 3).

A baixa qualidade da bebida de café, de grãos originados da árvore, pode estar relacionada com o número elevado de fungos do gênero Aspergillus sp. A presença deste gênero, desde o tempo 0 , pode indicar uma maior participação deste fungo nos processos fermentativos que alteram a qualidade da bebida de café, em especial o morfotipo Aspergillus sp1, que foi encontrado em maior frequência no tempo inicial (0 dia)

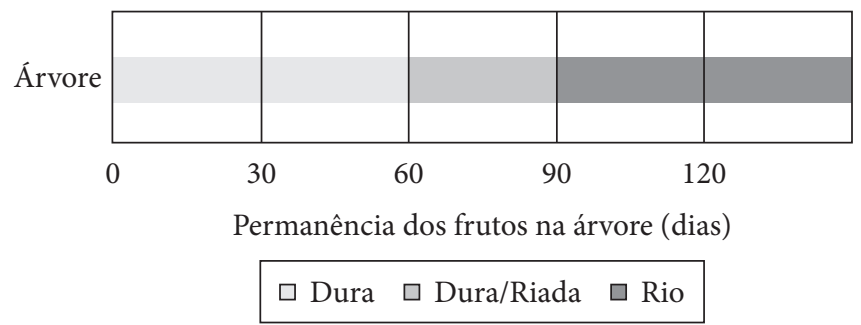

Figura 3. Qualidade da bebida de café de grãos cv. Iapar 59 da árvore da região de Londrina - PR (safra 2004/2005). Fonte: DECAF-PR; IAPAR; EMATER; CCCNP; BCML.

e diminuindo ao passar das colheitas. Portanto, este foi o morfotipo com frequência predominante em todos os tempos de colheita de grãos originados da árvore. Deste modo, a qualidade da bebida no tempo 0 (dura) pode estar relacionada com a alta frequência do gênero Aspergillus sp., pois Pimenta e Vilela (2003) obtiveram, no tempo 0, uma bebida considerada apenas mole, com uma frequência de Aspergillus sp. baixa, tendo um aumento nos demais tempos de colheita. Isso difere dos dados obtidos neste trabalho, uma vez que ocorreu uma piora na qualidade da bebida desde o início da colheita (tempo 0).

Na bebida de grãos coletados do solo observou-se também uma piora na qualidade, pois com o passar do tempo os grãos se tornam mais suscetíveis ao ataque de fungos. Além disso, quando a fermentação provocada pelos fungos é prolongada, a infecção torna-se acentuada e inicia-se a produção de compostos responsáveis pelo sabor desagradável (PIMENTA; VILELA, 2003) (Figura 4). 
Os níveis de Ocratoxina $\mathrm{A}$, em relação à origem dos grãos e aos diferentes tempos de colheita, podem ser observados na Tabela 2.

Os níveis de ocratoxina detectados nas amostras de café analisadas, em alguns casos, estão acima dos valores permitidos por países europeus, onde o nível máximo de ocratoxina $\mathrm{A}$ foi delimitado em $5 \mu \mathrm{g} / \mathrm{kg}$ em cereais e $1 \mu \mathrm{g} / \mathrm{kg}$ em alimentos destinados a crianças. No Brasil ainda não foram adotadas medidas semelhantes (PRADO et al., 2000), existindo apenas legislação para aflotoxinas.

Os gêneros Aspergillus, Penicillium e Fusarium são os mais frequentemente associados aos grãos contaminados com micotoxinas em níveis que os tornam impróprios para o consumo (YIANNIKOURIS; JOUANY, 2002). Especificamente associados à OTA, destacam-se os gêneros Aspergillus e Penicillium (MAGNOLI et al., 2004). Em países de clima tropical as espécies pertencentes ao gênero Aspergillus são as principais responsáveis pela produção de OTA em alimentos e as espécies de Penicillium são mais comuns a climas temperados (WHO, 2002).

Esta análise foi de extrema importância para mostrar que, apesar do morfotipo Aspergillus sp1 ter sido encontrado em maior número em grãos da árvore, provavelmente não deve ser produtor de ocratoxina. Entretanto, em uma única amostra, na $5^{\text {a }}$ colheita, aos 120 dias, foram detectados altos teores de ocratoxina. Novas análises se fazem necessárias, uma vez que apenas esta amostra apresenta teores muito elevados em relação aos demais resultados.

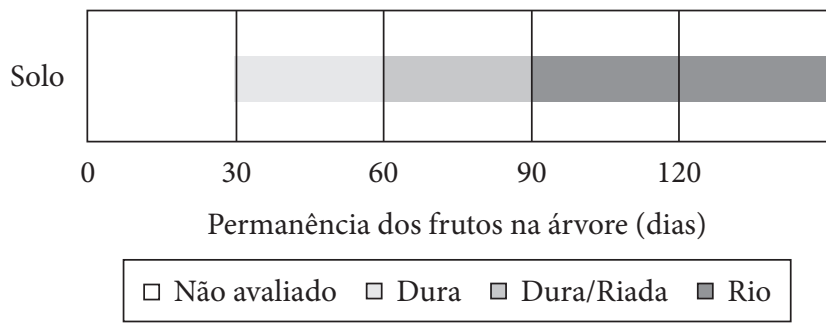

Figura 4. Qualidade da bebida de café de grãos cv. Iapar 59 do solo da região de Londrina - PR (safra 2004/2005). Fonte: DECAF-PR; IAPAR; EMATER; CCCNP; BCML.
Deve-se ressaltar que, no solo, os isolados do gênero Aspergillus sp1 foram encontrados em menor número em relação aos demais morfotipos do gênero Aspergillus, observando-se claramente que houve uma maior diversidade dos morfotipos pertencentes a esse gênero. Possivelmente, alguns destes morfotipos tiveram papel importante como produtores de ocratoxina.

Baixos níveis de Ocratoxina foram detectados por outros autores. Prado et al. (2000), estudando a incidência de ocratoxina A em café torrado e moído e em café solúvel consumidos na cidade de Belo Horizonte, MG, detectaram níveis de ocratoxina A não expressivos em termos de contaminação.

Pimenta e Vilela (2003) não detectaram a presença de ocratoxina A em amostras de grãos de café submetidos a diferentes tempos de repouso antes da secagem. Segundo Gonçalvez, Pinto e Felicio (2001), isso pode ocorrer porque a ocratoxina A é um metabólito secundário produzido por fungos em resposta às condições ambientais.

Entretanto, em trabalhos realizados por diferentes autores, foram detectados valores significativos de ocratoxinas. Micco et al. (1989) avaliaram 627 amostras de grãos de café verde provenientes do Brasil, Costa Rica, México e África, e afirmaram que 56 amostras (9\%) estavam contaminadas com ocratoxina A em níveis que variaram entre 0,5 e 360 ng. $\mathrm{g}^{-1}$.

Furlani, Soarez e Oliveira (1999) analisaram 50 amostras de café verde provenientes do Paraná, São Paulo, Minas Gerais, Espírito Santo, Roraima e Bahia. Encontraram ocratoxina em 15 (30\%) amostras, em níveis que variaram entre 0,8 e 117,4 ng.g ${ }^{-1}$.

O presente trabalho pretendeu, portanto, contribuir com o conhecimento da diversidade da microbiota presente nos grãos de café, visando à identificação de espécies fúngicas que possam alterar o sabor da bebida e, ainda, produzir micotoxinas. O sabor da bebida é um importante fator a ser considerado quando de sua exportação e a manutenção de sabor e odor agradáveis é primordial para o consumo desta. A presença de micotoxinas nos grãos, por sua vez, leva a um problema de saúde pública, em que diversos efeitos tóxicos, pela sua ingestão, podem ser deflagrados no homem e em outros animais.

Tabela 2. Análise dos níveis de ocratoxina (OTA) do café da cv. Iapar 59 do solo e da árvore da região de Londrina - PR (safra 2004/2005).

\begin{tabular}{|c|c|c|c|c|c|c|c|}
\hline \multirow[t]{2}{*}{ Data } & \multirow[t]{2}{*}{ Dias } & \multirow[t]{2}{*}{ Local } & \multicolumn{5}{|c|}{ OTA $(\mu \mathrm{g} / \mathrm{kg})$} \\
\hline & & & Amostra I & Amostra II & Amostra III & Amostra IV & Amostra V \\
\hline \multirow{2}{*}{$1^{\text {a }} 27 / 06$} & 0 & árvore & nd & 3,63 & nd & nd & nd \\
\hline & & solo & 7,75 & nd & nd & nd & 0,84 \\
\hline \multirow[t]{2}{*}{$2^{\text {a }} 27 / 07$} & 30 & árvore & nd & nd & nd & nd & nd \\
\hline & & solo & nd & nd & nd & nd & 21,58 \\
\hline \multirow[t]{2}{*}{$3^{\text {a } 27 / 08}$} & 60 & árvore & nd & nd & nd & nd & nd \\
\hline & & solo & 0,85 & 1,42 & nd & nd & nd \\
\hline \multirow[t]{2}{*}{$4^{\text {a }} 27 / 09$} & 90 & árvore & nd & 1,7 & nd & nd & nd \\
\hline & & solo & 5,13 & 1,18 & 0,25 & 11,28 & 0,8 \\
\hline \multirow[t]{2}{*}{$5^{\text {a } 27 / 10}$} & 120 & árvore & 0,21 & nd & 42,49 & 0,64 & nd \\
\hline & & solo & nd & nd & nd & nd & nd \\
\hline
\end{tabular}

Fonte: LACQSA - Equipe da Dra. Eugênia Azevedo Vargas - MAPA-MG. 


\section{Conclusões}

- O número de fungos isolados foi maior nos grãos de café da variedade IAPAR 59 provenientes da árvore do que do solo;

- Os gêneros isolados foram: Acremonium, Fusarium, Paecilomyces, Mucor, Penicillium, Absidia e Aspergillus, sendo que este apresentou maior diversidade (12 morfotipos) estando presente na maior parte dos tempos de estudo;

- O morfotipo Aspergillus sp1 apresentou a maior frequência de isolados da árvore e Aspergillus sp7 a maior frequência de isolados no solo;

- Observou-se uma piora na qualidade da bebida de grãos coletados, tanto na árvore quanto no solo, em função de sua permanência em seus locais de origem;

- Foram encontrados elevados níveis de ocratoxina nos grãos de café, indicando que os gêneros isolados são, potencialmente, produtores de micotoxinas; e

- Para a obtenção de uma bebida de melhor qualidade devese evitar a permanência prolongada dos grãos na árvore e no solo.

\section{Agradecimentos}

Ao Centro de Microscopia Eletrônica (CME) da Universidade Federal do Paraná.

Ao Labmicro (Laboratório de Microbiologia e Biologia Molecular) - Universidade Federal do Paraná.

\section{Referências bibliográficas}

AESCHBACH, M. K. et al. Isolamento de fungos de grãos de café da variedade Iapar 59 associados à qualidade de bebida do café. Curitiba, 2004. 48 p. Monografia (Bacharelado em Ciências Biológicas) - Universidade Federal do Paraná - UFPR.

BARNETT, H. C.; HUNTER, B. B. Illustrated genera of imperfect fungi. 3 ed. Minneapolis: Burgess Publications, 1987. p. 218.

CARVALHO, L. M. et al. Aspectos morfofisiológicos dos cultivares de cafeeiro catuaí-vermelho e conilon. Pesquisa Agropecuária Brasileira, v. 36, n. 3, p. 411-416, 2001.

CARVALHO, V. D. de; CHALFOUN, S. M. Cafeicultura, tecnologias de produção, gerenciamento e comercialização: colheita, preparo e armazenamento. 1 ed. Lavras: D4 videographics, 1999. CR-ROM.

EMBRAPA CAFÉ: Histórico. Disponível em: < http://www.embrapa. br/cafe/ > Acesso em: Abril de 2007.

FRANCO, B. D. G.; LANDGRAF, M. Microbiologia dos alimentos. São Paulo: ATHENEU, 2005. p. 182.

FURLANI, R. P. Z.; SOAREZ L. M. V.; OLIVEIRA, P. L. Avaliação de métodos para determinação de ocratoxina em cafés verdes e torrados. Revista do Instituto Adolfo Lutz, v. 58, n. 2, p. 87-89, 1999.

GONÇAlVEZ, E.; PINTO, M. M.; FELICIO, J. D. Análise de micotoxinas no Instituto Biológico de 1989 a 1999. Biológico, v. 63, n. 1/2, p. 15-19, 2001.
HAZEN, E. L.; GORDON, M. A.; REED, F. C. Laboratory identification of pathogenic fungi simplified. 3 ed. Springfield: Charles C. Thomas, 1973.

HERRERA, T.; ULLOA, M. El reino de los hongos: Micología básica y aplicada. 1 ed. México: Universidad Nacional Autónoma de México: Fondo de Cultura Económica, 1990. p. 552.

HOOG, G. S. de; GUARRO, J. Atlas of Clinical Fungi. Spain: Universitat Rovira i Virgili, 2004.

KERN, M. E. Medical mycology: A self- instructional text. 3 ed. Philadelphia: F. A. Davis Company, 1988.

KERN, M. E.; BLEVINS, K. S. Micologia médica - Texto e Atlas. 2 ed. São Paulo: PREMIER, 1999. p. 256.

KLICH, M. A.; PITT, J. I. Common Aspergillus species and their teleomorphs. Austrália: Commonwealth Scientific and Industrial research Organization, 1988. p. 116.

KRUG, H. P. A origem dos cafés duros. Boletim de Agricultura, v. 48, p. 397-406, 1947.

KRUG, H. P. Cafés duros II: um estudo sobre a qualidade dos cafés de varrição. Revista do Instituto de Café, v. 27, n. 163, p. 1393-1396, 1940.

LARONE, D. H. Medically important fungi: A guide to identification. 2 ed. New York: Elsevier, 1987. p. 230.

MAGNOLI, C. et al. Survey of mycoflora and ochratoxin a in dried vine fruits from Argentina markets. Letters in Applied Microbiology, v. 39, n. 4, p. 326-331, 2004.

MENEZES, M.; OLIVEIRA, S. M. A. Fungos fitopatogênicos. Pernambuco: UFRPE, Imprensa Universitária, 1993. p. 227.

MICCO, C. et al. A study the contamination by ochratoxin a of green and roasted coffee beans. Food Additives and Contaminants, v. 6, n. 3, p. 333-339, 1989.

PIMENTA, J. C.; VILELA E. R. Composição microbiana e ocratoxina no café (Coffea arabica L.) submetido a diferentes tempos de espera de secagem. Ciência e Agrotecnologia, v. 27, n. 6, p. 1315-1320, 2003.

PIMENTEL-GOMES, F. P. Curso de Estatística experimental. 13 ed. Piracicaba: Universidade de São Paulo, 1990. p. 466.

PRADO, G. et al. Incidência de ocratoxina A em café torrado e moído e em café solúvel consumido na cidade de Belo Horizonte, MG. Ciência e Tecnologia de Alimentos, v. 20, n. 2, p. 192-196, 2000.

STANDARD methods for examination of water and wastewater. 21 ed. Washington: APHA, 2005. p. 1368.

STOFELLA, D. R. E. Variabilidade morfológica da região faríngea dos arcos branquiais de algumas espécies de peixes (Teleostei), estudada através da microscopia eletrônica de varredura. Curitiba, 1994. 125 p. Tese (Doutorado em Biologia Celular) Universidade Federal do Paraná - UFPR.

VIEIRA, S. Análise de variância (ANOVA). São Paulo: ATLAS, 2006. p. 204.

World Health Organization - WHO/FAO. Meeting of the joint FAO/ WHO. Report of the 56 ed. Expert Committee on Food Additives, 2002. p. 6-15.

YIANNIKOURIS, A.; JOUANY, J. P. Mycotoxins in feeds and their fate in animals: a review. Animmal Research, v. 5, p. 81-99, 2002. 